\title{
Chinese dragon sign: splenic artery calcification
}

\author{
Subramaniyan Ramanathan ${ }^{1,2}$ (D)
}

Published online: 8 May 2019

(c) The Author(s) 2019

'Chinese dragon sign' describes the appearance of tortuous calcified splenic artery on an abdominal radiograph $[1,2]$. The Dragon is a mythical creature and denoted generally as snake-like with four legs and considered one of the 12 animals in the Chinese zodiac [3] (Fig. 1). The tortuous course with arterial wall calcification resembles the body of dragon, and the more tortuous coiled segment near the splenic hilum resembles the head of dragon (Fig. 2).

Splenic artery tortuosity and calcification are common findings in the abdominal radiograph and computed tomography (CT) of the abdomen of elderly and diabetic population. Splenic artery shows a relatively linear course in the pediatric population and tortuosity develops with increasing age due to mismatch in the growth of vessel and distance between its origin and splenic hilum [4]. Calcification is usually medial (located in tunica media) with circumferential and continuous tram track appearance on radiographs. It is often an incidental finding but can be associated with aneurysms [5]. Splenic artery aneurysm is the commonest visceral artery aneurysm and has a small risk of rupture [6]. It can be calcified although splenic artery calcification has no relationship with the development or rupture of aneurysms. Splenic artery aneurysms cannot be confidently diagnosed on a radiograph and needs contrast-enhanced CT [7].

Subramaniyan Ramanathan

drrmsubbu@gmail.com

1 Department of Clinical Imaging, Al-Wakra Hospital, Hamad Medical Corporation, PO Box: 82228, Doha, Qatar

2 Department of Radiology, Weil Cornell Medical College, Doha, Qatar 


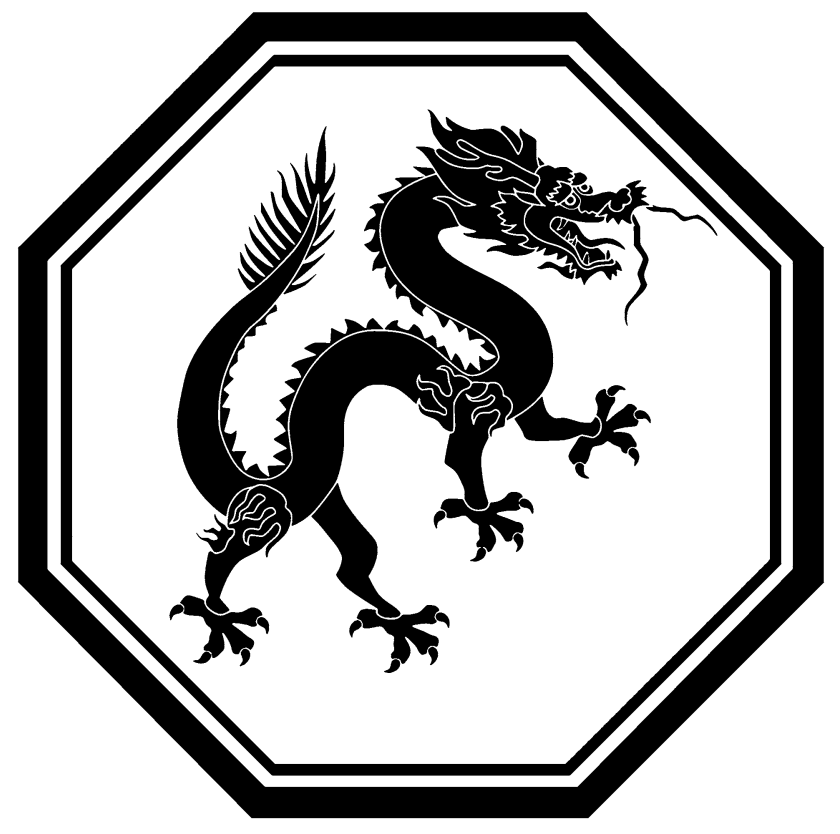

Fig. 1 Image of The Chinese dragon Source: https://en.wikipedia.org/ wiki/Dragon_(zodiac) \#/media/File:Dragon.svg. Accessed 4 April 2018. This file is licensed under the Creative Commons AttributionShareAlike 3.0 Unported license
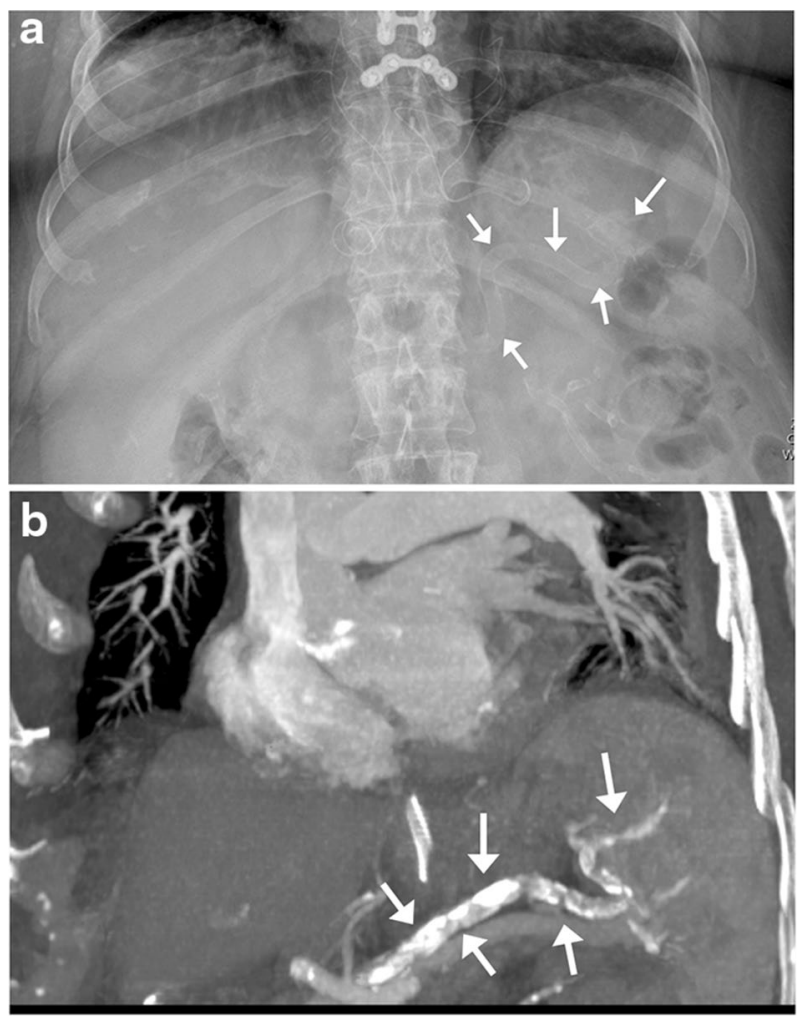

Fig. 2 a Radiograph of the upper abdomen showing the tortuous and calcified splenic artery in the left upper quadrant (arrows). b Coronal view of contrast-enhanced CT showing the tortuous and calcified splenic artery reaching the splenic hilum (arrows)
Acknowledgement Open Access funding provided by the Qatar National Library.

\section{Compliance with ethical standards}

Conflict of interest All the authors declare that they have no conflicts of interest.

Research involving human participants and/or animals All procedures performed in studies involving human participants were in accordance with the ethical standards of the institutional and/or national research committee and with the 1964 Helsinki declaration and its later amendments or comparable ethical standards.

Informed consent Informed consent was obtained from all individual participants included in the study.

Open Access This article is distributed under the terms of the Creative Commons Attribution 4.0 International License (http://creativeco mmons.org/licenses/by/4.0/), which permits unrestricted use, distribution, and reproduction in any medium, provided you give appropriate credit to the original author(s) and the source, provide a link to the Creative Commons license, and indicate if changes were made.

\section{References}

1. Begg J (ed) (2006) Abdominal X-rays Made Easy. 2nd ed edn. Elsevier Health Sciences, Edinburgh

2. Xiang H, Han J, Ridley WE, Ridley LJ (2018) Chinese dragon: Splenic artery. J Med Imaging Radiat Oncol 62 Suppl 1:64. https ://doi.org/10.1111/1754-9485.12_12784

3. Wikipedia contributors. Chinese dragon. Wikipedia, The Free Encyclopedia. March 28, 2019, 22:54 UTC. Available at: https ://en.wikipedia.org/w/index.php?title=Chinese_dragon\&oldid $=889935372$. Accessed April 4, 2019. Accessed 4 April 2019

4. Golder WA (2008) [Tortuosity and calcification of the splenic artery. More than an additional finding]. Radiologe 48 (11):10661067, 1069-1074. https://doi.org/10.1007/s00117-008-1631-z

5. Moretti D, Almiron MN, Rigo EM (2013) [Calcification of the splenic artery]. Med Clin (Barc) 141 (6):278. https://doi. org/10.1016/j.medcli.2013.02.018

6. Al-Habbal Y, Christophi C, Muralidharan V (2010) Aneurysms of the splenic artery - a review. Surgeon 8 (4):223-231. https://doi. org/10.1016/j.surge.2009.11.011

7. Abbas MA, Stone WM, Fowl RJ, Gloviczki P, Oldenburg WA, Pairolero PC, Hallett JW, Bower TC, Panneton JM, Cherry KJ (2002) Splenic artery aneurysms: two decades experience at Mayo clinic. Ann Vasc Surg 16 (4):442-449. https://doi.org/10.1007/ s10016-001-0207-4

Publisher's Note Springer Nature remains neutral with regard to jurisdictional claims in published maps and institutional affiliations. 